Pacific Journal of Mathematics

ON GENERALIZED FORMS OF APOSYNDESIS 


\section{ON GENERALIZED FORMS OF APOSYNDESIS}

\section{Charles L. Hagopian}

If a point set is both connected and closed it is called a continuum. The structure of a nonlocally connected continuum can be described in terms of its aposyndetic properties. In this paper various forms of continuum aposyndesis, that is, aposyndesis with respect to subcontinua, are considered. It is shown that the presence of any of these forms of aposyndesis in a compact metric continuum which is totally nonconnected im kleinen (not connected im kleinen at any point) insures nonsemi-local-connectedness on a dense open subset of the continuum and the set of weak cut points in each open subset of the continuum has cardinality at least $c .^{1}$ A weak cut point theorem for compact plane continua is established. An example is given which indicates that this result does not hold in Euclidean 3-space. Near aposyndesis, a generalization of aposyndesis, is introduced. It is shown that the presence of this property in a totally nonaposyndetic, separable, metric continuum implies the existence of uncountably many weak cut points.

DEFINITION. Let $x, y$, and $z$ be distinct points of a continuum $M$. If every subcontinuum of $M$ which contains $x$ and $y$ also contains $z$, then $z$ is said to cut $M$ weakly between $x$ and $y$. A point $z$ of $M$ is said to be a weak cut point of $M$ if there exist two points $x$ and $y$ in $M$ such that $z$ cuts $M$ weakly between $x$ and $y$.

Definition. Let $S$ be a subset of a continum $M$ and let $x$ be a point of $M-S$. If $M$ contains a continuum $H$ and an open set $U$ such that $x \in U \subset H \subset M-S$, then $M$ is said to be aposyndetic at $x$ with respect to $S$. Note that if $M$ is a regular Hausdorff continuum, $M$ being aposyndetic at a point $p$ with respect to every closed set in $M-\{p\}$ is equivalent to $M$ being connected im kleinen at $p$. Let $x$ be a point of a continuum $M$; if for each point $y$ of $M-\{x\}, M$ is aposyndetic at $x$ with respect to $y$, then $M$ is said to be aposyndetic at $x$.

Let $S$ is a subset of a continuum $M$. If $x$ is a point of $M-S$ and $M$ is not aposyndetic at $x$ with respect to $S$, then $M$ is said to be nonaposyndetic at $x$ with respect to $S$.

2. Continuum aposyndesis. In the introduction it is pointed

${ }^{1}$ For a related result see [5, Th. 15]. For definitions of unfamiliar terms and phrases see [7] and [9]. 
out that connectedness im kleinen at a point of a regular Hausdorff continuum can be thought of in terms of aposyndesis at that point with respect to closed sets which do not contain the point. This concept can be generalized by considering aposyndesis at a point with respect to closed connected sets (i.e., continua) which do not contain the point.

Definition. Let $M$ be a continuum and $p$ and $q$ be two distinct points in $M$. If, for each continuum $K$ in $M-\{p\}$ which contains $q$, $M$ is aposyndetic at $p$ with respect to $K$, then $M$ is said to have property $A$ at $p$ with respect to $q$. If, for every point $x$ in $M-\{p\}$, $M$ has property $A$ at $p$ with respect to $x$, then $M$ is said to have property $A$ at $p$.

Obviously, if a regular Hausdorff continuum $M$ is connected im kleinen at a point $p$ in $M$, then $M$ has property $A$ at $p$. An example due to F. B. Jones indicates that the converse of this statement is false [6, Example 3]. The compact plane continuum described by Jones has property $A$ at a point $y$ and is not connected im kleinen at $y$. The point $y$ in this continuum is a weak cut point. The following theorem indicates that a compact plane continuum has these properties (property $A$ and nonconnectedness im kleinen) at a point only if the point is a weak cut point of the continuum.

LEMma. If a compact plane continuum $M$ is not connected im kleinen at a point $x$, then for each open set $U$ in the plane which contains $x$, there exists a pair of points $\{y, z\}$ in $U \cap M$ such that $M$ is nonaposyndetic at $x$ which respect to $\{y, z\} .^{2}$

Proof. Assume that there is an open set $U$ containing $x$ such that $M$ is aposyndetic at $x$ with respect to every pair of points in $U \cap M$. Since $M$ is not connected im kleinen at $x$, there exists a circular region $G$ such that $\mathrm{Cl} G$ (the closure of $G$ ) is contained in $U$ and a sequence $K_{1}, K_{2}, K_{3}, \ldots$ of distinct components of $M \cap \mathrm{Cl} G$ such that (1) for each positive integer $i, K_{i}$ contains the point $y_{i}$ of a sequence $y_{1}, y_{2}, y_{3}, \cdots$ of points of $J$ (the boundary of $G$ ) converging to the point $y$ and (2) $x$ is in the limit inferior of $K_{1}, K_{2}, K_{3}, \cdots$.

Since $M$ is aposyndetic at $x$ with respect to any pair of points of $U \cap M, M$ is aposyndetic at $x$ with respect to $y$. Therefore, there exists a continuum $H$ in $M-\{y\}$ such that $x$ is contained in Int $H$ (the interior of $H$ ). Each component of $H \cap G$ has a limit point in $J$. Hence there exists a subsequence $K_{1}^{\prime}, K_{2}^{\prime}, K_{3}^{\prime}, \ldots$ of $K_{1}, K_{2}, K_{3}, \ldots$

${ }^{2}$ This lemma is stated in [6]. The proof does not appear in the literature. 
such that for each $i, K_{i}^{\prime}$ contains the point $z_{i}$ of a sequence $z_{1}, z_{2}, z_{3}, \ldots$ of points of $J$ converging to the point $z$ of $J-\{y\}$.

By assumption $M$ is aposyndetic at $x$ with respect to $\{y, z\}$. Hence there is a continuum $L$ such that $x \in \operatorname{Int} L \subset L \subset M-\{y, z\}$. Let $A$ and $B$ denote disjoint subarcs of $J$ containing $y$ and $z$ respectively as nonendpoints) such that $(A \cup B) \cap L=\varnothing$. Since every component of $L \cap G$ has a limit point in $J$, there exist three positive integers, $i, j$, and $k$, such that each of $K_{i}^{\prime}, K_{j}^{\prime}$, and $K_{k}^{\prime}$ intersects each of $A, B$, and $J-(A \cup B)$. Since $J-(A \cup B)$ has exactly two components, some two of these three continua must intersect the same component of $J-(A \cup B)$. This leads to a contradiction of Theorem 28 of [7, p. 156].

THEOREM 1. If a compact plane continuum $M$ has property $A$ at a point $x$ and is not connected im kleinen at $x$, then $x$ is a weak cut point of $M$.

Proof. By the preceding lemma, there exists a pair of points $\{y, z\}$ in $M-\{x\}$ such that $M$ is nonaposyndetic at $x$ with respect to $\{y, z\} . M$ must be aposyndetic at $x$ with respect to each continuum in $M-\{x\}$ since $M$ has property $A$ at $x$. Therefore no subcontinuum of $M$ in $M-\{x\}$ contains both $y$ and $z$.

Example 1. A compact continuum $M$ in Euclidean 3-space which has property $A$ at a point $p$, and is not connected im kleinen at $p$, may fail to be cut weakly by $p$. To see this define $A_{i}=\{(0,0,1 / n)\}$ $n=i, i+1, i+2, \cdots\}$. Let $C_{1}$ be the join of $\mathrm{Cl} A_{1}$ with the point $(1,0,0)$. For $i=2,3, \cdots$, define $C_{i}$ to be the join of $\mathrm{Cl} A_{i}$ with the point $(1,1 / i, 0)$. Let $M=\bigcup_{i=1}^{\infty} C_{i}$. See Figure 1 . Let $p$ be the point $(0,0,0)$. Any subcontinuum in the complement of $p$ intersect only finitely many of the $C_{i}$ 's. It follows that $M$ has property $A$ at $p$. Clearly $M$ is not connected im kleinen at $p$ and $p$ does not cut $M$ weakly between any two points in $M-\{p\}$. Note that $M$ is not semilocally-connected at $p$.

THEOREM 2. If a regular Hausdorff continuum $M$ is semi-locallyconnected at a point $p$ and has property $A$ at $p$, then $M$ is connected im kleinen at $p .^{3}$

Proof. Assume that $M$ is not connected im kleinen at $p$. First it will be shown that under this assumption $p$ must be a weak cut

${ }^{3}$ This has been previously observed for compact Hausdorff continua [1, Th. 4]. 


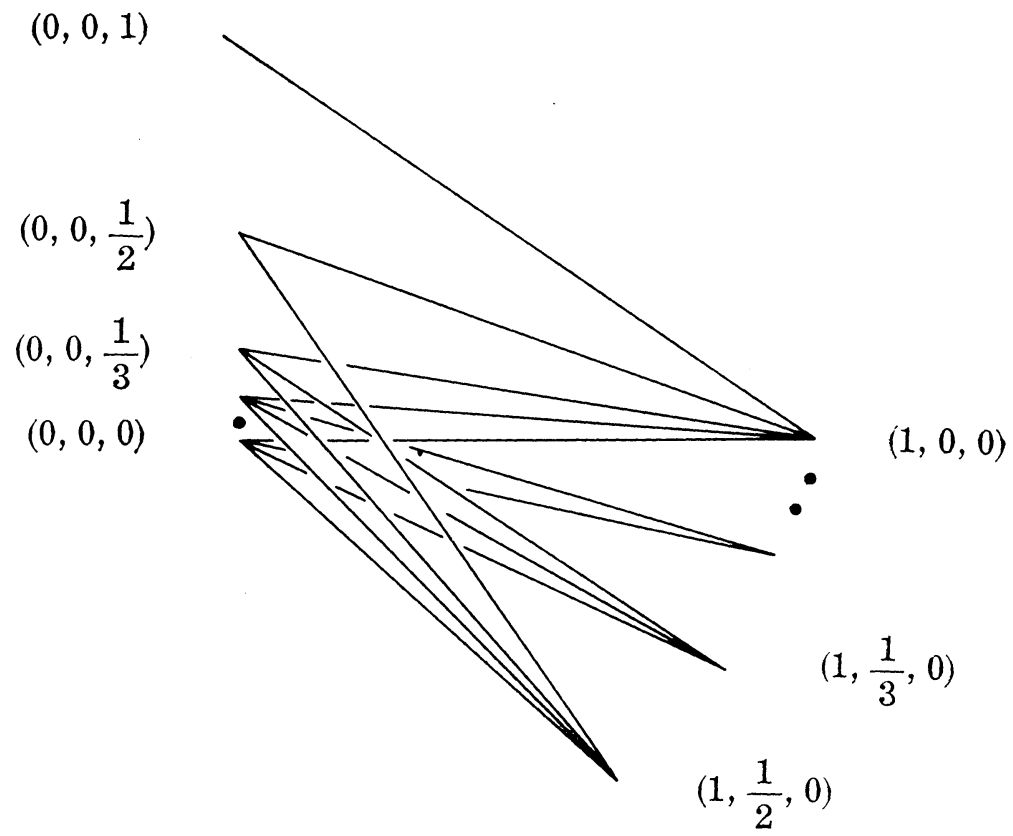

FIGURE 1.

point of $M$.

Since $M$ is not connected im kleinen at $p$ and is semi-locallyconnected at $p$, there exists an open set $U$ in $M$ containing $p$ such that $M$ is nonaposyndetic at $p$ with respect to $M-U$, and $M-U$ has only a finite number of components. If $p$ is not a weak cut point then the components of $M-U$ can be joined together by a finite number of continua in $M-\{p\}$. Let $L$ be the union of these continua. Every continuum containing $p$ in its interior must meet the continuum. $(M-U) \cup L$. But this contradicts the fact that $M$ has property $A$ at $p$. Therefore $p$ must be a weak cut point.

Since $M$ is semi-locally-connected at $p$ and $p$ is a weak cut point, $p$ must separate $M$ [8, Th. 6.2]. Suppose that for each component $C$ of $M-\{p\}$ which meets $M-U$, the set $C \cup\{p\}$ is a connected subspace of $M$ which is aposyndetic at $p$ with respect to $(C \cup\{p\})-U$. Then in each of these subspaces there is a continuum which contains $p$ in its interior, relative to the subspace, which does not meet $M-U$. The sum of these continua and the components of $M-\{p\}$ which do not meet $M-U$ form a continuum in $M$ which contains $p$ in its interior and misses $M-U$. This contradicts the choice of $U$. Therefore there is a component $C$ in $M-\{p\}$ such that the subspace $C \cup\{p\}$ is nonaposyndetic at $p$ with respect to $(C \cup\{p\})-U$. It follows that the subspace $C \cup\{p\}$ is not connected im kleinen at $p$. Let $H$ be the subspace $C \cup\{p\}$. Note that $H$ is semi-locally-connected at $p$, since 
$M$ is semi-locally-connected at $p$.

The subspace $H$ has property $A$ at $p$. To see this let $Q$ denote a subcontinuum of $H-\{p\}$. Because $M$ has property $A$ at $p$, and $Q$ is a subcontinuum of $M$, there exists a subcontinuum $K$ of $M-Q$ which contains $p$ in its interior. Since $p$ is a separating point, the set $H \cap K$ is a subcontinuum of $H$ and $p$ is in the interior of $H \cap K$ relative to $H$. Therefore $H$ has property $A$ at $p$.

By applying to the subspace $H$ the argument presented in the second paragraph of this proof, one can conclude that $p$ must cut $H$ weakly and therefore separate $H$. But this is impossible since $H$ consists of the point $p$ and a component of $M-\{p\}$. Hence $M$ is connected im kleinen at $p$.

In bicompact $T_{1}$ continua, property $A$ and local connectedness are equivalent as global properties, since if a bicompact $T_{1}$ continuum has property $A$ everywhere, then it is aposyndetic at each of its points and therefore semi-locally-connected [5, Th. 0], and from Theorem 2 it follows that the continuum is everywhere connected im kleinen and therefore locally connected.

It is clear that a $T_{1}$ continuum $M$ has property $A$ at a point $p$ with respect to a point $q$ if and only if for each open set $G$ in $M$ $\{q\}$ which contains $p, M$ is aposyndetic at $p$ with respect to the $q$ component of $M-G$. From this point of view one can generalize this property as follows.

Definition. Let $p$ and $q$ be distinct points of a continuum $M$. If for each open set $G$ in $M-\{q\}$ which contains $p$, there exists a point $r$ in $G$ such that $M$ is aposyndetic at $r$ with respect to the $q$-component of $M-G$, then $M$ is said to have property $B$ at $p$ with respect to $q$. If for each point $x$ in $M-\{p\}, M$ has property $B$ at $p$ with respect to $x$, then $M$ is said to have property $B$ at $p$. If $M$ has property $B$ at each point of $M$, then $M$ is said to have property $B$.

Obviously, if a continuum $M$ contains a dense subset $D$ such that $M$ has property $A$ at each point of $D$, then $M$ has property $B$. The following example indicates that property $B$ is considerably weaker than property $A$.

EXAMPLE 2. There exists a compact plane continuum $M$ which has property $B$ and is totally nonaposyndetic (not aposyndetic at any of its points) hence does not have property $A$ at any point.

Let $M_{1}, M_{2}, \cdots$ be a sequence of closed plane point sets defined by induction as follows. Let $S$ be the unit disk and let $M_{1}$ be the closure of the union of the (topological) disk sequence $D_{1}, D_{2}, \ldots$ 


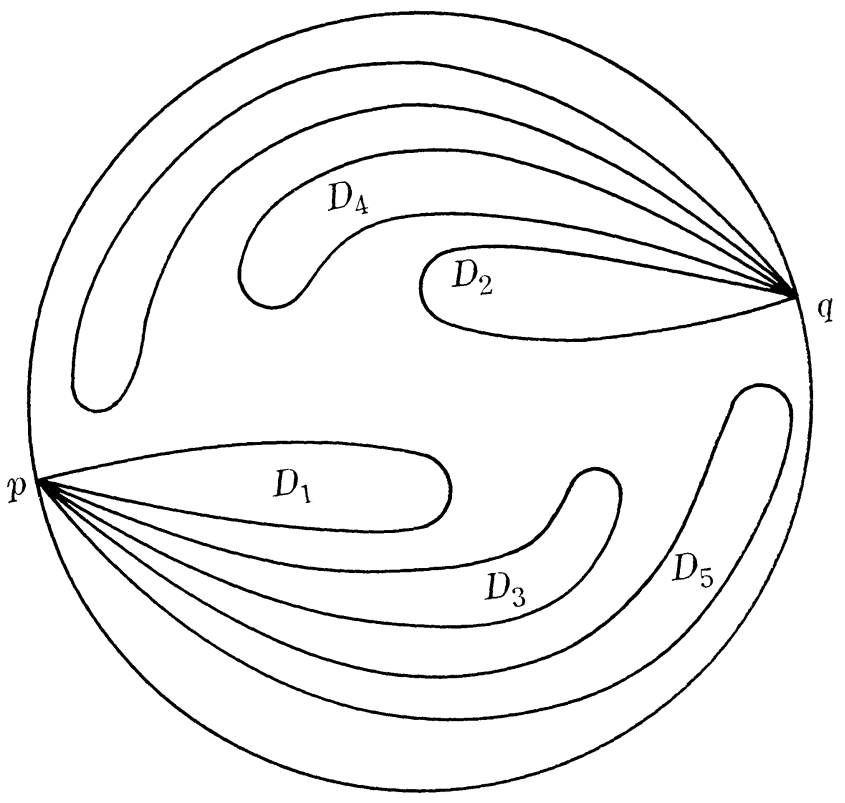

FIGURE 2.

indicated in Figure 2. The boundary of $S$ is the limiting set of $D_{1}$, $D_{2}, \ldots$. The diameter of each of $D_{1}, D_{2}, \ldots$ is greater than $3 / 4$. Let $p$ and $q$ be the two separating points in $M_{1}$. Note that $M_{1}$ is nonaposyndetic at each point of the boundary of $S$ with respect to one of $p$ and $q$.

Assume $M_{n}$ to be defined and let $D_{1}^{\prime}, D_{2}^{\prime}, \ldots$ be a counting of the disks in $M_{n}$. Let $f_{i}$ be a homeomorphism of $S$ onto $D_{i}^{\prime}$ such that the distance from $f_{i}(p)$ to $f_{i}(q)$ is greater than $(1 / 4)+(1 / n+3)$. Let $M_{n+1}=\mathrm{Cl}\left[\bigcup_{i=1}^{\infty} f_{i}\left(M_{1}\right)\right]$. The homeomorphisms of $S$ onto the disks of $M_{n}$ are chosen in such a way that the disks in $M_{n+1}$ will be of diameter greater than $(1 / 2)+(1 / n+3)$ and the set of separating points in $M_{n+1}$ is $1 / n+1$ dense in $M_{n}$. Define $M=\bigcap_{n=1}^{\infty} M_{n}$.

$M$ has property $B$. To see this let $x$ and $y$ be two points in $M$ and let $G$ be an open set in $M-\{y\}$ containing $x$. Let $C$ be the $y$ component of $M-G$. Since the point set consisting of homeomorphic images of $\{p, q\}$ is dense in $M$, there is a point $s$ in $M \cap G$ which is a separating point in $M_{n}$ (for some $n$ ). There exists a disk $D$ in $M_{n}$ such that $y$ is not in $D$ and $s$ separates $D-\{s\}$ from $M_{n}-D$ in $M_{n}$. It follows that $M \cap D$ is a continuum in $M-C$ which has an interior point in $G$.

It is clear that $M$ is nonaposyndetic at each point which is on the boundary of some defining continuum $M_{n}$ in $S$. Let $x$ be a point of $M$ which is in the interior of $M_{n}$ for every positive integer $n$. There exist a nest of disks $d_{1}, d_{2}, \ldots$ and two sequences of points, $s_{1}, s_{2}, \ldots$ 
and $t_{1}, t_{2}, \cdots$, such that (1) for each positive integer $n$, the point $x$ is contained in $d_{n}$; (2) $d_{n}$ is a maximal disk in $M_{n}$; (3) the point $s_{n}$ separates $d_{n+1}-\left\{s_{n}\right\}$ from $\left(d_{n}-d_{n+1}\right) \cap M_{n+1}$ in $M_{n+1}$; and (4) $t_{n}$ is the other point which separates $d_{n} \cap M_{n+1}$. Note that for each $n, M$ is nonaposyndetic at $s_{n}$ with respect to $t_{n}$. If $x$ is a limit point of $s_{1}$, $s_{2}, \cdots$, then there exists a point $t$ in $M$, distinct from $x$, which is a limit point of the sequence $t_{1}, t_{2}, \cdots$, such that $M$ is nonaposyndetic at $x$ with respect to $t$ [5, Th. 1]. If $x$ is not a limit point of $s_{1}, s_{2}, \cdots$, then there exists a point $s$ in $M$, distinct from $x$, which is a limit point of this sequence. It follows that $M$ is nonaposyndetic at $x$ with respect to $s$. Therefore $M$ is totally nonaposyndetic.

DEFINITION. Let $p$ be a point of a continuum $M$. If there exists a point $q$ in $M-\{p\}$ such that $M$ has property $B$ at $p$ with respect to $q$, then $M$ is said to have property $C$ at $p$.

Obviously, if a continuum has property $B$ at a point $p$, then it has property $C$ at $p$. One can see that property $C$ is weaker than property $B$ by considering the Cantor Cone. This continuum has property $C$ at each point which is in the interior of an arc, but it has property $B$ only at the vertex.

THEOREM 3. If a compact metric continuum $M$ has property $C$ at each point of a dense $G_{\delta}$ subset of $M$ and is totally nonconnected $i m$ kleinen on a dense $G_{\delta}$ subset of $M$, then $M$ is totally nonsemilocally-connected on a dense open subset of $M$.

Proof. Let $U$ be an open set in $M$. If one can show that there exists an open subset $G$ of $U$ such that $M$ is not semi-locally-connected at any point of $G$, then the existence of the dense open subset of $M$ with the desired condition with follow immediately.

The open set $U$ contains an open set $V$, no component of which contains an open set [3, Th. 2]. It follows that for each point $x$ in $V, M$ is nonaposyndetic at $x$ with respect to $M-V$. Define $D_{i}=$ $\{x \in V \mid$ for some $y$ in $M-S(x, 1 / i)(S(x, 1 / i)$ is the circular open set in $M$ with the point $x$ as center and with radius $1 / i), M$ has property $B$ at $x$ with respect to $y$ \}. Since $\bigcup_{i=1}^{\infty} D_{i}$ is a second category subset of $V$, for some positive integer $n$, the set $\mathrm{Cl} D_{n}$ contains an open set in $V$. It follows that there exists an open set $W$ in $V$ such that $W$ contains a dense subset $D$ with the condition that for each point $x$ in $D$, there exists a point $y$ in $M-W$ such that $M$ has property $B$ at $x$ with respect to $y$.

If $M$ is totally nonsemi-locally-connected on $W$, then $W$ has the 
required conditions. Assume that this is not the case. That is, there exists a point $p$ in $W$ such that $M$ is semi-locally-connected at $p$. There exists an open set $Q$ containing $p$ in $W$ such that $M-Q$ has only a finite number of components. Suppose that $p$ is not a weak cut point. Join together the components of $M-Q$ with a finite number of continua in $M-\{p\}$. Let $L$ be the union of these continua and let $K$ be the continuum $(M-Q) \cup L$. The set $M-K$ is open and contained in $Q$. Since $D$ is dense in $W$ and $M-W$ is contained in $K$ there exist a point $x$ in $D \cap(M-K)$ and a point $y$ in $K$ such that $M$ has property $B$ at $x$ with respect to $y$. But this is impossible since $M$ is nonaposyndetic at each point of $M-K$ with respect to $K$. Therefore $p$ is a weak cut point in $M$.

Since $M$ is semi-locally-connected at $p, p$ is a separating point in $M$ and each component of $M-\{p\}$ is both open and closed relative to $M-\{p\}$. Let $X$ be a component of $M-\{p\}$ which meets $M-Q$. The set $S=X \cup\{p\}$ is a connected subspace of $M . S$ is semi-locallyconnected at $p$. The point $p$ is not a weak cut point in $S$ for if it were it would also separate $S$ which is clearly impossible. $S-Q$ has only a finite number of components. Join there components together with a finite number of continua in $X$. Let $F$ denote the union of these continua with $S-Q$. The set $F$ is a continuum in $S-\{p\}$ which contains $S-Q$. The set $G=X-F$ is open in $M$. Let $x$ be a point in $G$ and assume that $M$ is semi-locally-connected at $x$. Each open subset of $G$ which contains $x$ cuts $M$ weakly between $p$ and $F$ (i.e., each continuum in $M$ which meets both $F$ and $p$ must also meet each open subset of $G$ which contains $x$ ). To see this suppose that there exist an open set $R$ containing $x$ in $G$ and there exists a continuum $H$ in $M-R$ which meets both $p$ and $F$. It follows that $M-Q$ is contained in one component of $M-R$. But for some point $s$ in $R$ there exists a point $t$ in $M-W$ such that $M$ has property $B$ at $s$ with respect to $t$. Therefore there exists a point $r$ in $R$ such that $M$ is aposyndetic at $r$ with respect to the $t$-component of $M-R$. This is a contradiction since $M-Q$ is contained in the $t$-component of $M-R$ and $M$ is nonaposyndetic at $r$ with respect to $M-Q$. It follows that $x$ cuts $M$ weakly between $p$ and $F$. Since $M$ is semi-locally-connected at $x, M$ is separated by $x$ between $p$ and $F . S-\{x\}$ can be written as the union of two mutually separated sets $P$ and $E$ such that $p$ is contained in $P$ and $F$ is contained in $E . \quad P \cup\{x\}$ is a subcontinuum of $M$ which has a nonvoid interior and is contained in $Q$. This contradicts the fact that no component of $Q$ contains an open set. Therefore $M$ is totally nonsemi-locally-connected on $G$.

THEOREM 4. If a compact metric continuum $M$ is nonsemi-locallyconnected at each point of a $G_{\delta}$ subset which is dense in $M$, then the 
set of weak cut points in each open subset of $M$ has cardinality at least $c$.

Proof. Let $U$ be an open subset of $M$. Define the set $D=\{x \in$ $M \mid$ for each open set $V$ containing $x$, there exists an open subset $W$ of $V$ containing $x$ such that $M$ is aposyndetic at $x$ with respect to each point of the boundary of $W$ \}. If $D$ is dense in $U$, then there exists a dense $G_{\delta}$ subset $J$ of $U$ such that each point of $J$ is a weak cut point in $M$ [4, Th. 4].

Suppose that $D$ is not dense in $U$. There exists an open set $G$ in $U-D$. Since $G$ is second category, there exist a point $x$ in $G$ and a point $r$ in $M$ such that if $y$ is a point of $M$ and $M$ is nonaposyndetic at $x$ with respect to $y$, then $y$ cuts $M$ weakly between $x$ and $r$ [2, Th. 4]. There exists an open set $Q$ containing $x$ in $G$ such that for each open subset $R$ of $Q$ there is a point $y$ in the boundary of $R$ such that $M$ is nonaposyndetic at $x$ with respect to $y$. There are $c$ open sets in $Q$ which contain $x$ and have mutually disjoint boundaries. It follows that there are $c$ points in $Q$ which cut $M$ weakly between $x$ and $r$.

THeOREM 5. If a compact metric continuum $M$ has property $C$ at each point of a dense $G_{\delta}$ subset of $M$ and is totally nonconnected im kleinen on a dense $G_{j}$ subset of $M$, then each open subset of $M$ contains a set of weak cut points of $M$ which has cardinality $c$.

Proof. $M$ is totally nonsemi-locally-connected on a dense open subset of $M$ (Theorem 3). The conclusion follows from Theorem 4 .

COROLlaRY. If a compact metric continuum $M$ has property $B$ and is totally nonconnected im kleinen on a dense $G_{\delta}$ subset of $M$, then each open subset of $M$ contains a set of weak cut points of $M$ which has cardinality $c$.

Note that if a compact metric continuum $M$ is totally nonconnected im kleinen on a dense $G_{\dot{\delta}}$ subset of $M$ and contains a dense subset $D$ such that $M$ has property $A$ at each point of $D$, then $M$ contains a dense $G_{\delta}$ set of weak cut points of $M[4, T h .4]$. However, the existence of such continua is still an open question.

3. Near aposyndesis. In $\S 2$ property $B$ is introduced as a weaker form of continuum aposyndesis. In this section aposyndesis (aposyndesis with respect to points) is generalized in a similar fashion.

Definition. A continuum $M$ is said to be nearly aposyndetic at 
a point $p$ in $M$ with respect to a point $q$ in $M$ if each open set in $M$ containing $p$ contains a point $r$ such that $M$ is aposyndetic at $r$ with respect to $q$. Let $p$ be a point of $M$; if for each point $q$ in $M-\{p\}$, $M$ is nearly aposyndetic at $p$ with respect to $q$, then $M$ is said to be nearly aposyndetic at $p$.

It is easily seen that if a continuum $M$ has property $C$ at a point $p$ and is not nearly aposyndetic at $p$, then $p$ must be a weak cut point in $M$. Note that the Cantor Cone has these two properties at each point of a dense open set.

THeORem 6. A compact metric continuum $M$ is not nearly aposyndetic at a point $p$ with respect to a point $s$ if and only if there exists an open set $G$ in $M$ containing $p$, such that if $U$ is a nonvoid open subset of $G$, then $s$ cuts $M$ weakly between some two points in $U$.

Proof. If $M$ is not nearly aposyndetic at $p$ with respect to $s$, then there exists an open set $G$ containing $p$ such that $M$ is nonaposyndetic at each point of $G$ with respect to $s$. This open set $G$ has the desired property [2, Th. 2].

To see that the condition is sufficient, assume that $M$ is nearly aposyndetic at $p$ with respect to $s$. Let $G$ be an open set in $M$ containing $p$. There exists a point $x$ in $G$ such that $M$ is aposyndetic at $x$ with respect to $s$. Therefore there is a continuum $K$ and an open set $U$ such that $x \in U \subset K \subset M-\{s\}$. It follows that $s$ does not cut $M$ weakly between any two points of the open set $G \cap U$ in $G$.

If a continuum $M$ has property $B$, then $M$ is nearly aposyndetic (that is, $M$ is nearly aposyndetic at each of its points). It follows that the totally nonaposyndetic continuum $M$ in Example 2 is nearly aposyndetic. One can see from this example that near aposyndesis is considerably weaker than aposyndesis. $M$ in Example 2 is totally nonsemi-locally-connected. The following example indicates that this is not necessarily the case for totally nonaposyndetic continua which are nearly aposyndetic.

EXAMPLE 3. There exists a compact nearly aposyndetic, totally nonaposyndetic continuum $M$ in $E^{3}$ (Euclidean 3-space) which is semilocally-connected on a dense open subset of $M$.

Let $C$ be the Cantor set and its image on the interval $[-1,0]$. For each point $z$ of $C$ define the set

$$
\begin{aligned}
S_{z}=\left\{(x, y, z) \in E^{3} \mid x\right. & =0 \text { or } x=1 \text { and } 0 \leqq y \leqq 1, \text { or } \\
y & =0 \text { or } y=1 \text { and } 0 \leqq x \leqq 1\} .
\end{aligned}
$$


Let $S=\bigcup_{z \in C} S_{z}$. Define the continuum $M$ to be the decomposition of $S$ obtained as follows. For each positive real number $z$ in $C$, identify the point $(z, 0, z)$ with the point $(z, 0,0)$. For each negative real number $z$ in $C$, identify the point $(-z, 1, z)$ with the point $(-z, 1,0)$. See Figure 3. $M$ is semi-locally-connected at each point which is not in the $X Y$-plane. Note that $M$ contains a Cantor set of weak cut points.

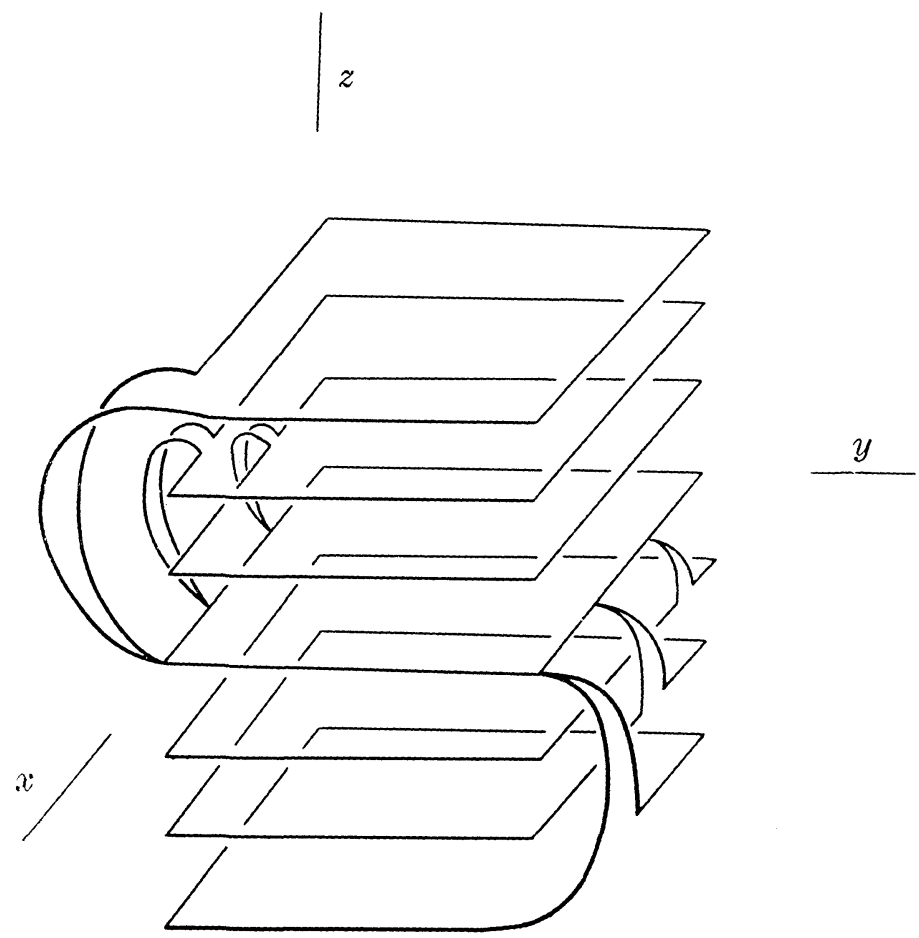

FIGURE 3.

It is possible for a compact totally nonaposyndetic metric continuum to have only one weak cut point [5, Example 1]. However, if the continuum is also nearly aposyndetic then one is assured of the existence of more than countably many weak cut points.

THEOREM 7. If a compact metric continuum $M$ is nearly aposyndetic and totally nonaposyndetic, then $M$ has uncountably many weak cut points.

Proof. Assume that $M$ has only countably many weak cut points. Let $s_{1}, s_{2}, \ldots$ be a counting of these points. Let $Q$ denote a countable dense subset of $M$. Since $M$ is totally nonaposyndetic, $M$ contains a dense $G_{\delta}$ subset $I$ such that if $x$ is a point in $I$ and $M$ is nonaposyn- 
detic at $x$ with respect to a point $y$, then $y$ cuts $x$ weakly from each point of $Q-\{y\}$ in $M$ [2, Corollary 1]. For each positive integer $i$, define

$$
D_{i}=\left\{x \in I \mid s_{i} \text { cuts } x \text { from each point of } Q-\left\{s_{i}\right\}\right\} \text {. }
$$

$\mathrm{U}_{i=1}^{\infty} D_{i}=I$. Since $I$ is second category, there is a positive integer $n$ such that $D_{n}$ is somewhere dense. Let $G$ be an open set in Cl $D_{n}$ which does not contain $s_{n}$. Note that $G$ has the property described in Theorem 6. It follows that $M$ is not nearly aposyndetic at any point of $G$ with respect to $s_{n}$. But this is a contradiction. Therefore $M$ must contain uncountably many weak cut points.

\section{BIBLIOGRAPHY}

1. H. S. Davis, A note on connectedness im kleinen, Proc. Amer. Math. Soc. 19 (1968), $1237-1241$.

2. E. E. Grace, Cut sets in totally nonaposyndetic continua, Proc. Amer. Math. Soc.

9, (1958), 98-104.

3. - Totally nonconnected im kleinen continua, Proc. Amer. Math. Soc. 9, (1958), 818-821.

4. - Cut points in totally non-semi-locally-connected continua, Pacific J. Math. 14 (1964), 1241-1244.

5. F. B. Jones, Concerning non-aposyndetic continua, Amer. J. Math. 70 (1948), 403413.

6. - Concerning aposyndetic and non-aposyndetic continua, Bull. Amer. Math. Soc. 58 (1952), 137-151.

7. R. L. Moore, Foundations of point set theory, Amer. Math. Soc. Coll. Pub. 13 Rhode Island, 1962.

8. G. T. Whyburn, Semi-locally-connected sets, Amer. J. Math. 61 (1939), 733-749.

9. - Analytic topology, Amer. Math. Soc. Coll. Pub. 18, Rhode Island, 1963.

Received January 19, 1970, and in revised form February 24, 1970.

Arizona State University

Sacramento State College 


\section{PACIFIC JOURNAL OF MATHEMATICS}

EDITORS

H. SAMELSON

Stanford University

Stanford, California 94305

RichaRd PIERCE

University of Washington

Seattle, Washington 98105
J. DUGUNDJI

Department of Mathematics

University of Southern California

Los Angeles, California 90007

RICHARD ARENS

University of California

Los Angeles, California 90024

\section{ASSOCIATE EDITORS}

E. F. BECKENBACH

B. H. NeumanN

F. WOLF

K. YOSHIDA

\section{SUPPORTING INSTITUTIONS}

UNIVERSITY OF BRITISH COLUMBIA

CALIFORNIA INSTITUTE OF TECHNOLOGY

UNIVERSITY OF CALIFORNIA

MONTANA STATE UNIVERSITY

UNIVERSITY OF NEVADA

NEW MEXICO STATE UNIVERSITY

OREGON STATE UNIVERSITY

UNIVERSITY OF OREGON

OSAKA UNIVERSITY

UNIVERSITY OF SOUTHERN CALIFORNIA
STANFORD UNIVERSITY

UNIVERSITY OF TOKYO

UNIVERSITY OF UTAH

WASHINGTON STATE UNIVERSITY

UNIVERSITY OF WASHINGTON

AMERICAN MATHEMATICAL SOCIETY CHEVRON RESEARCH CORPORATION TRW SYSTEMS

NAVAL WEAPONS CENTER 


\section{Pacific Journal of Mathematics}

May, 1970

Johan Aarnes, Edward George Effros and Ole A. Nielsen, Locally compact

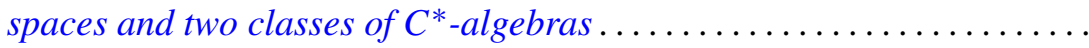

Allan C. Cochran, R. Keown and C. R. Williams, On a class of topological

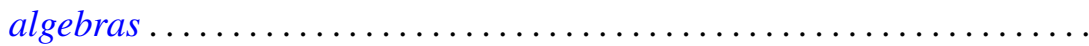

John Dauns, Integral domains that are not embeddable in division rings ....

Robert Jay Daverman, On the number of nonpiercing points in certain

crumpled cubes.....................................

Bryce L. Elkins, Characterization of separable ideals ................

Zbigniew Fiedorowicz, A comparison of two naturally arising uniformities

on a class of pseudo-PM spaces ...........................

Henry Charles Finlayson, Approximation of Wiener integrals of functionals

continuous in the uniform topology ........................

Theodore William Gamelin, Localization of the corona problem ...........

Alfred Gray and Paul Stephen Green, Sphere transitive structures and the

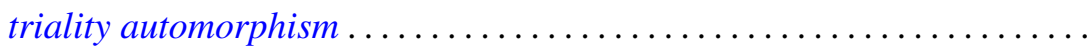

Charles Lemuel Hagopian, On generalized forms of aposyndesis ..........

J. Jakubík, On subgroups of a pseudo lattice ordered group ...............

Cornelius W. Onneweer, On uniform convergence for Walsh-Fourier

series..................................

Stanley Joel Osher, On certain Toeplitz operators in two variables ...

Washek (Vaclav) Frantisek Pfeffer and John Benson Wilbur, On the

measurability of Perron integrable functions............

Frank J. Polansky, On the conformal mapping of variable regions...

Kouei Sekigawa and Shûkichi Tanno, Sufficient conditions for a Riemannian manifold to be locally symmetric ...................

James Wilson Stepp, Locally compact Clifford semigroups ....

Ernest Lester Stitzinger, Frattini subalgebras of a class of solvable Lie

algebras ................................

George Szeto, The group character and split group algebras...

Mark Lawrence Teply, Homological dimension and splitting torsion

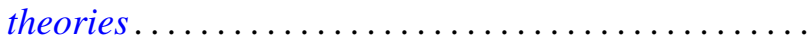

David Bertram Wales, Finite linear groups of degree seven. II ...

Robert Breckenridge Warfield, Jr., An isomorphic refinement theorem for

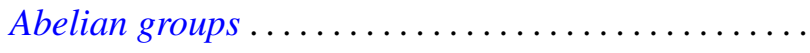

James Edward West, The ambient homeomorphy of an incomplete subspace

of infinite-dimensional Hilbert spaces................

Peter Wilker, Adjoint product and hom functors in general topology ...

Daniel Eliot Wulbert, A note on the characterization of conditional 